\title{
Surface Discharges and Flashover Voltages in Nanocomposite XLPE Samples
}

\author{
C. Papadakis \\ Democritus University of Thrace \\ Department of Electrical and Computer Engineering \\ Power Systems Laboratory \\ Xanthi, Greece
}

\section{G. Danikas}

Democritus University of Thrace

Department of Electrical and Computer Engineering

Power Systems Laboratory

Xanthi, Greece

\author{
Y. Yin \\ Shanghai Jiao Tong University \\ Department of Electrical Engineering \\ School of Electronic, Information and Electrical \\ Engineering, Shanghai, China \\ C. Charalambous \\ Democritus University of Thrace \\ Department of Electrical and Computer Engineering \\ Power Systems Laboratory \\ Xanthi, Greece
}

\begin{abstract}
DC cable insulation is a field of intensive research activity. Special attention is being given to polymer nanocomposites, as promising insulation for such cables. Relatively little is known regarding surface discharges and flashover voltages for the aforementioned materials. In this paper, a comparison is made between samples of cross-linked polyethylene insulation with added $\mathrm{MgO}$ nanofillers and samples of pure polyethylene w.r.t. the behavior of surface discharges and flashover voltages in arrangements of water droplets of various conductivities on the said polymeric surfaces under the influence of uniform electric fields. Experimental evidence indicates that the flashover voltages of XLPE with MgO nanofillers are higher that the ones obtained with pure PE.
\end{abstract}

Keywords-discharge; flashover; cable; XPLE; nanocomposite

\section{INTRODUCTION}

Power transmission through DC voltage becomes increasingly popular, especially in countries with extended areas, such as China or the USA. Recently, efforts are being undertaken in the direction of polymer nanocomposite insulation for DC applications [1-3]. A possible candidate for such applications is the cross linked polyethylene (XLPE) with added $\mathrm{MgO}$ nanofillers $0.5 \mathrm{wt} \%$. Surface discharges and subsequent flashovers constitute, among others, a danger for such insulation [4]. In this paper, surface discharges and flashover voltages of the above mentioned polymer nanocomposite are compared with those of pure polyethylene (PE). Water droplets of various conductivities are put on the polymeric surfaces and the discharge phenomena are studied under the influence of uniform electric fields.

\section{EXPERIMENTAL SET-UP}

In the context of this work, a transformer with a rated voltage of $20 \mathrm{kV}$ was used. The electrodes used were of brass and they are shown in Figure 1. The distance between the electrodes was set at $2.5 \mathrm{~cm}$ in all experiments. Uniform electric fields were applied in all experiments. The water droplets were positioned on the polymeric surface with the aid of a $10 \mathrm{ml}$ syringe and a special arrangement consisting of a metallic frame and three rules, one of which had two laser indicators. The positioning of the droplets w.r.t. the electrodes can be seen in Figure 2. The insulation materials investigated were pure PE and XLPE with added $\mathrm{MgO}$ nanofillers (having $0.5 \mathrm{wt} \%$ nanofillers). The water droplets were of the following conductivities: $0,8 \mu \mathrm{S} / \mathrm{cm}, 100 \mu \mathrm{S} / \mathrm{cm}, 200 \mu \mathrm{S} / \mathrm{cm}, 500 \mu \mathrm{S} / \mathrm{cm}$, $1000 \mu \mathrm{S} / \mathrm{cm}, 2000 \mu \mathrm{S} / \mathrm{cm}, 5000 \mu \mathrm{S} / \mathrm{cm}$ and $10000 \mu \mathrm{S} / \mathrm{cm}$. Each single droplet has a $0.05 \mathrm{ml}$ volume.

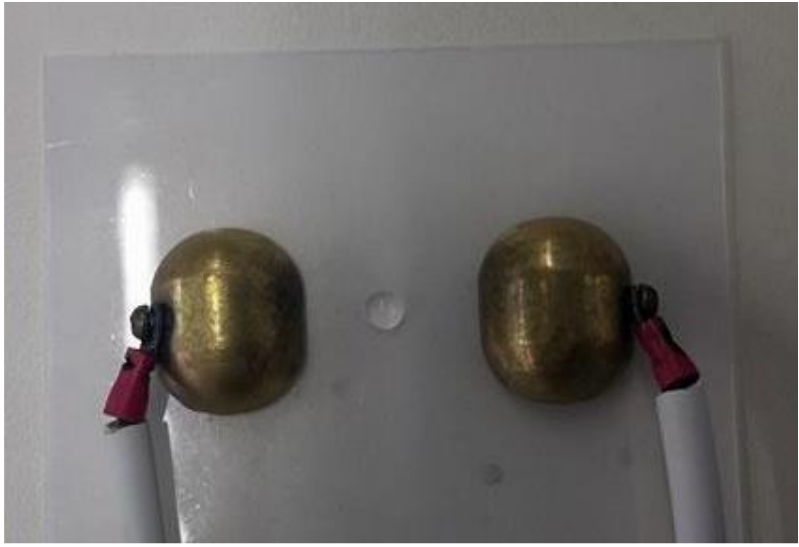

Fig. 1. The brass electrodes used for the experiments 

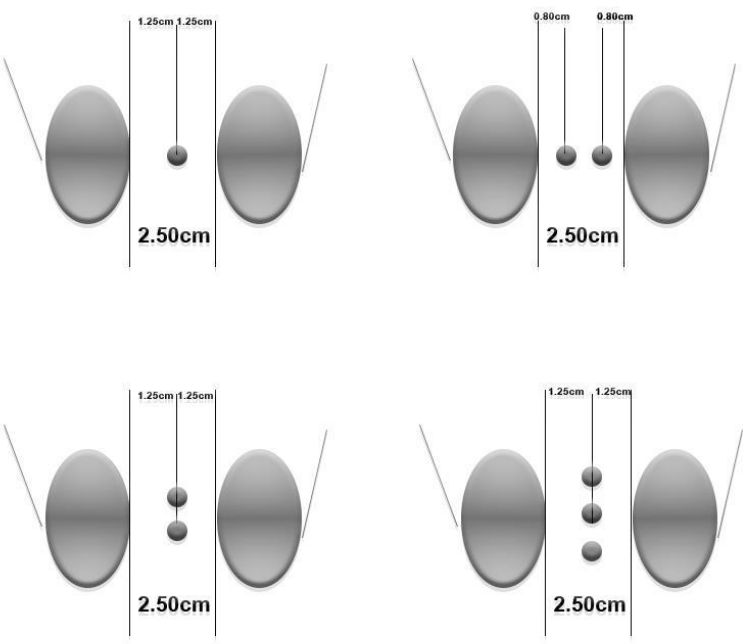

Fig. 2. The various water droplet arrangements used

The experimental procedure was the following: Once the water drops of specified volume and conductivity was placed on the insulating material in one of the aforementioned arrangements, the output voltage of the power supply was gradually increased until the flashover of the gap and the recording of the breakdown voltage. After cleaning the insulating surface with alcohol, we repeated the same procedure by increasing the voltage of the power supply until the last recorded value not to bring about the flashover of the gap was reduced by $1,2 \mathrm{kV}$. At this point we left the output voltage of the power supply steady for five minutes to provide the necessary time for the process of deformation of the drop to be developed, the occurrence of partial discharges and/or ultimately the flashover to occur. If there was no flashover, the voltage was increased at $0.4 \mathrm{kV}$ steps until the occurrence of a flashover. This was the value of flashover voltage that was finally recorded. The parameters that were investigated were: 1) the water droplet arrangements, 2) water conductivity, 3) water droplet volume, 4) the insulating material used and 5) the positioning of the droplets w.r.t. the electrodes.

\section{EXPERIMENTAL RESULTS AND DISCUSSION}

A water droplet on a polymeric surface is affected by the surface tension of the liquid, the surface tension of the solid, the interfacial tension between the droplet and the solid as well as by the applied electric field. The latter causes deformation/elongation of the droplet. Such deformation will affect the distribution of the electric field, which in turn will again act upon the droplet. There is a so to speak a feedback mechanism, which will eventually cause local field intensifications and microdischarges. Dry zones will ensue and finally the flashover will result [5]. In Figure 3, the flashover voltages of pure PE, for water droplet arrangements, such as those of Figure 2 (each water droplet of $0.05 \mathrm{ml}$ volume), are shown with varying conductivity. It is evident that the twodroplet horizontal arrangement gives the lower results, whereas the other three droplet arrangements seem to give more or less similar flashover voltages for the various conductivities, with the one droplet arrangement giving the best results and with the three droplet arrangement giving somehow lower flashover voltages in higher conductivities. Evidently the positioning of the droplets w.r.t. the electrodes plays a vital role in determining the flashover voltage.

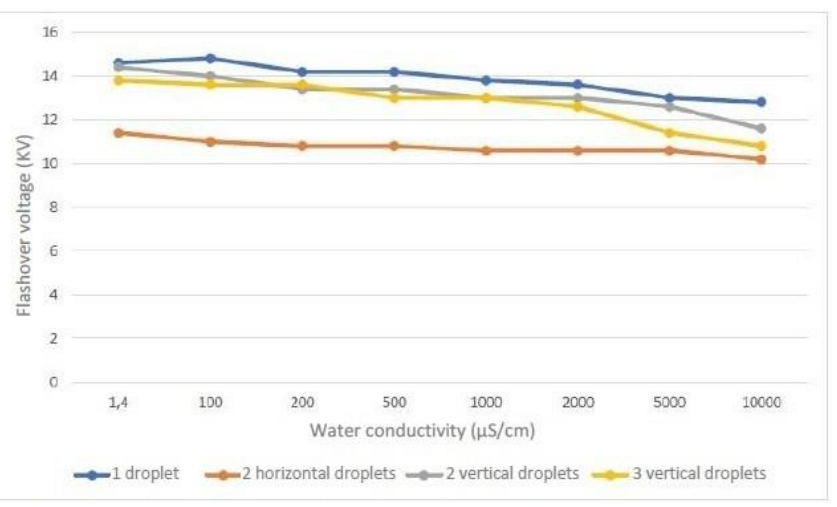

Fig. 3. Flashover voltages for various droplet arrangements on PE surfaces

In Figure 4, the flashover voltages for the XLPE with added $\mathrm{MgO}$ nanofillers are shown (each droplet having $0.05 \mathrm{ml}$ volume). Again we observe that the two droplet horizontal arrangement gives the worst flashover voltages whereas the other three droplet arrangements give somehow similar flashover voltages. In this case again, the three droplet arrangement gives lower flashover voltages at higher conductivities.

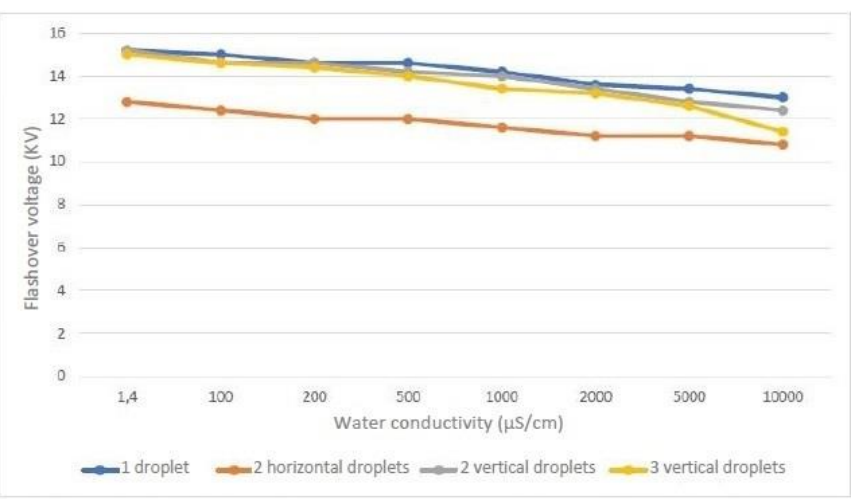

Fig. 4. Flashover voltages for various droplet arrangements on XLPE surfaces with added $\mathrm{MgO}$ nanofillers

If one compares Figures 3 and 4, it seems that XLPE with added nanofillers gives higher flashover voltages compared to pure PE, for all droplet arrangements and for all conductivities tested. Although the experiments performed in the context of the present work are not of long duration, one may see a difference between XLPE with nanofillers and pure PE. The reason as to why this should be so was given some years ago in [6-7], where it was proposed that with polymer nanocomposites, discharge activity tends to force the nanofilers (or agglomerations of them) to come onto the surface, hindering thus the propagation of surface discharges. Recent SAXS measurements of XLPE samples (with added nanofillers) as well as of pure PE samples showed that the 
surface of the former after discharging tends to be more compact [8]. This is in agreement with [6-7]. XLPE with $\mathrm{MgO}$ nanofillers after discharge shows increasing crystallinity, which again can be explained with increasing nanofillers agglomerates. The aforementioned interpretations seem to be in agreement with [9], where it was reported that there can be surface modifications of the nanocomposites and of the nature of the interface in the region around the nanofillers. These views are also shared in $[10,11]$. It is true that the present research was carried out using $\mathrm{AC}$ voltages whereas it is intended that the tested materials will be used for DC transmission. Nevertheless, after the DC transmission the voltage has to be changed to $\mathrm{AC}$, and this fact underlines the importance of studying the above materials also under $\mathrm{AC}$ conditions.

Further steps towards a better clarification can be taken, such as more experiments with a larger variety of droplet arrangements, experiments with XLPE having various $\mathrm{MgO}$ nanofiller percentages and comparative contact angle studies between XLPE with MgO nanofillers and pure PE. Especially about the latter, there were reports that the addition of nanofillers in XLPE increases the contact angle [12]. The interpretation related to the hardening of the nanocomposite surface needs to be further explored, especially in view of recent research indicating that nanofillers may accelerate the dissipation of surface space charge, i.e. rapid charge dissipation may be due to high shallow trap density created by nanofillers. Shallow traps can capture electrons and fast electrons can be converted to slower electrons [13].

\section{CONCLUSIONS}

In this paper, indications that the XLPE with added nanofillers of $\mathrm{MgO}$ performs better than pure PE regarding the flashover voltage, were presented. This may be due to the gradual erosion of the base polymer and the coming onto the surface of the nanocomposite of the nanofillers (or agglomerations of them) which eventually hinder the further propagation of surface discharges. More experiments will further elucidate the phenomena of surface discharge and flashover in nanocomposites.

\section{ACKNOWLEDGMENTS}

The samples of the present work have been prepared at Shanghai Jiao Tong University by the group of Prof. Yi Yin.

\section{REFERENCES}

[1] C. W. Reed, "An assessment of material selection for high voltage DC extruded polymer cables", IEEE Electrical Insulation Magazine, Vol. 33, No. 4, pp. 22-26, 2017

[2] T. Andritsch, A. Vaughan, G. C. Stevens, "Novel insulation materials for high voltage cable systems", IEEE Electrical Insulation Magazine, Vol. 33, No.4, pp. 27-33, 2017

[3] G. Melissinos, M. Danikas, "On Polymers Nanocomposites: Electrical Treeing, Breakdown models and Related Simulations", Engineering, Technology \& Applied Science Research, Vol. 8, No. 2, pp. 2627-2632, 2018

[4] S. C. Kechagia, M. G. Danikas, R. Sarathi, "Water droplets and breakdown phenomena on polymer nanocomposite surfaces under the influence of uniform electric fields", Malaysian Polymer Journal, Vol. 8, No. 2, pp. 41-47, 2013
[5] F. Obenaus, "Fremdschichtueberschlag und Kriechweglaenge", Elektrotechnik, Vol. 4, pp. 135-137, 1958

[6] M. Kozako, R. Kido, N. Fuse, Y. Ohki, T. Okamoto, "Difference in surface degradation due to partial discharges between polyamide nanocomposite and microcomposite", IEEE 2004 Annual Report of Conference on Electrical Insulation and Dielectric Phenomena (CEIDP), pp. 398-401, 2004

[7] M. Kozako, R. Kido, T. Imai, T. Ozaki, T. Shmizu, T. Tanaka, "Surface roughness change of epoxy/TiO2 nanocomposites due to partial discharges", International Symposium on Electrical Insulating Materials, Japan, pp. 661-664, 2005

[8] C. Charalambous, M. G. Danikas, Y. Yin, N. Vordos, J. W. Nolan, A. Mitropoulos, "Study of the behavior of water droplets under the influence of a uniform electric field on conventional polyethylene and on crosslinked polyethylene (XLPE) with $\mathrm{MgO}$ nanoparticles samples", Engineering, Technology \& Applied Science Research, Vol. 7, No. 1, pp. 1323-1328, 2017

[9] P. Prabhu, M. J. Thomas, "Influence of nanofillers on the surface electrical discharge resistance of epoxy insulation in HV apparatus", International Journal on Emerging Electrical Power Systems, Vol. 12, No. 4, DOI: 10.2202/1553-779X.2706, 2011

[10] R. Sarathi, A. K. Sahoo, Y. Chen, T. Tanaka, "Understanding surface discharge activity with epoxy silicon carbide nanocomposites", Polymer Engineering \& Science, Vol. 57, No. 12, pp. 1349-1355, 2017

[11] A. B. Poda, R. Dhara, Md. Afzalur Rab, P. Basappa, "Evaluation of aging in nanofilled polypropylene by surface discharges", IEEE Transactions on Dielectrics and Electrical Insulation, Vol. 23, No. 1, pp. 275-287, 2016

[12] P. A. Sharad, K. S. Kumar, "Application of surface modified XLPE nanocomposites for electrical insulation - partial discharge and morphological study", Nanocomposites, Vol. 3, No. 1, pp. 30-41, 2017

[13] Y. Z. Lv, Y. Zhou, C. R. Li, K. B. Ma, Q. Wang, W. Wang, S. N. Zhang, Z. Y. Zin, "Nanoparticle effects on creeping flashover characteristics of oil/pressboard interface", IEEE Transactions on Dielectrics and Electrical Insul.ation, Vol. 21, No. 2, pp. 556-562, 2014 